\title{
Space in the 20th Century Theatre: 2. Determination, Consequence and Assumption
}

\author{
Radivoje Dinulović* \\ University of Novi Sad, Faculty of Technical Sciences, Chair in Art Applied to Architecture, Serbia
}

\begin{abstract}
Citation: Dinulović R. Space in the 20th Century Theatre: 2 . Determination, Consequence and Assumption. SEE J Arch Des. $\quad 2015 \quad$ Nov $12 ;$
http://dx.doi.org/10.3889/seejad.2015.10008 Key words: 20th Century theatre; determination; consequence; assumption

Correspondence: Prof. Dr. Radivoje Dinulović, University of Novi Sad, Faculty of Technical Sciences, Chair in Art Applied to Architecture., Serbia. E-mail: radivoje.dinulovic@gmail.com Received: 06-Oct-2014; Revised: 20-Oct-2014; Accepted: 27-Oct-2015; Published: 12-Nov-2015

Copyright: () 2015 Radivoje Dinulović. This is an openaccess article distributed under the terms of the Creative Commons Attribution License, which permits unrestricted use, distribution, and reproduction in any medium, provided the original author and source are credited.

Competing Interests: The author have declared that no competing interests exist.
\end{abstract}

\begin{abstract}
BACKGROUND: Interaction of literature, visual and performing arts as well as media, especially in the second half of the twentieth century, has substantially transformed the technical and artistic resources the theatre uses.

AIM: The aim of this study is to present determination, consequence and assumption as parts of Space in the 20th Century Theatre.

MATERIAL AND METHODS: Three aspects of the architecture were described in details: determination consequence and assumption of the space in the 20th century theatre.

RESULTS: The idea of theatre is conveyed through houses, books, research documents, history and theory but it is also conveyed through "theatre people". This concept, can be and must be understood the two ways: as a guideline for a highly heterogeneous and inarticulate "global tribe", and at the same time, as the common name for members of a particular theatre - the theatre as a troupe, or theatre as a movement, but mostly the theatre as an institution of what we often call "the theatre house".

CONCLUSION: The causal system of relationships between the theatre house, theatre people and theatre as an idea (or the idea of theatre) is the central theme of my understanding of the definitions, values and
\end{abstract} purpose of theatre.
"Space concerns everyone connected with the theatre, from the architects who first design the building to the actors who play in it and the stage designers and directors who labour in it. Also (even if they are quite unaware of it) the audience, who we hope, will fill it."

\section{Sir John Gielgud [1]}

Interaction of literature, visual and performing arts as well as media, especially in the second half of the twentieth century, has substantially transformed the technical and artistic resources the theatre uses. At the same time, formal, technological and spatiallyfunctional differences between certain types of public scene events have been greatly reduced. Under the term "technology“ in this context I do not think of the "application of scientific knowledge for practical purposes“ (The New Oxford Dictionary of English, CDRom, 2001) [2], but of a "system of practical approaches, ... the entirety of resources that people employ to provide the objects of material culture". (Webster's Third New International Dictionary, str. 2348) [3].

The theme of different views on the relationship between technology and the space was thoroughly deliberated on the Yugoslav symposium titled Architecture and Technology, which the Chair for the development of architecture and arts has organized at the Faculty of Architecture in Belgrade in 1991 (see the Journal of history and theory of architecture and town De re Aedificatoria, No. 2, 1991) [4]. The term "spectacle" was extended to sports, political, promotional and other events thus making stadiums, sports halls, museums, galleries and even the public spaces of the city, from point of 
view of technical engineering, but also from the point of view of the programme, the "houses for spectacle" alongside the theatres, concert halls and cinemas. All these buildings and constructions are designed and equipped as typical venues for performing events. The typology of public events and the corresponding architectural structures and spaces is the subject of many studies at present day - from social and cultural, to theatrical and urban, but also one of the important aspects of planning and construction of houses and cities. This subject, however, which we would easily believe to be exclusively contemporary, was addressed in 15th century by Leon Battista Alberti in his "Ten Books on Architecture" (De Re Aedificatoria), devoting to it the seventh chapter of Book VIII ("Of the adorning Theatres and other Places for public Shows, and of their Usefulness") [5]. Alberti writes of those "whose job it is to give good example to others" through public events for which the key subject is "peace and leisure" (and they are dealing with poets, actors and musicians) as well as those related to war (wrestling, pugilism, shooting, jumping, running and "everything that fits the practical exercises of was force"). These events require different buildings, because they have different names - for poets, comedians, dramatists "and alike"- the theatre; for "noble youths" who are running coaches circuses; and lastly, to fight with wild animals amphitheatres [5]. Parallel existence and mutual interaction of different public events and facilities, therefore, are the traditional and enduring issues.

However, at this point I wish scrutinise the drama theatre in the narrow sense of the term, as a construction and as an institution.

Quite specifically, this means that in respect to content, character, artistic and production resources, the concept of theatre for me is a collective of all the activities involved in preparing, implementing and performing public performing events based on drama as a primary art form. In relation to the programme, nature and structure of physical space, under the term theatre I infer a complete architectural project, thought through, designed and built for the preparation and performance of dramatic plays.

Today, when we speak of space in the theatre, which still is a special phenomenon and a specific realm of human life, "the last public place where idealism is still an open issue" [6], the centre of our attention points to the articulation of space of theatre play - stage and auditorium. This spatial organisation is the result of institutionalisation of theatre arts, and it can progress and change based on the transformation of ideas about theatre, artistic and scenic resources, and also stage techniques and technology. However, we must always keep in mind the fact that the stage-auditorium space is only one of the elements in a complex physical structural system of the theatre. Theatre house, as a spatial result of this system, is not just a "tool for the spectacle" [7], but also responds to many diverse needs defined by dozens of functionally-technological lines (not just utilitarian), which, in turn, define theatre as an art form, as a production institution, as a social phenomenon, and as a programme in architecture. In broadest terms, any consideration of theatre space has to be placed in the context of another trinity relationship - the theatre as an artistic being, the architectural body of the theatre and the overall urban structure.

On the other hand, based on many definitions of theatre it is quite clear that the physical space within which any theatrical performance is to be enacted is the presumption of existence of theatre and scene arts. History of theatre, as well as theoretical and practical research on the subject of theatre of our time, in which the play has become "the only true subject of theatrology research" [8], presents us with the task of articulating the place of theatre performance - stage, and the place from which it is viewed from - the auditorium, as one of the basic defining features of physicality and spirituality of theatre in general. The questions of architectural structure of theatre houses have to be introduced in the whole discourse. Theatre event in the narrow sense of the term, everything that happens in the theatre in the area that we call the space of performance, and everything that happens during the time, metaphorically speaking, between raising and lowering the stage curtains at the end of the performance, is without a doubt the key issue of the theatre and of theatre architecture. But the theatre reduced only to the matter of performance might actually be, at least in relation to its physical aspects, "the most futile of all our efforts" and "the very image of what awaits all crafts, sooner or later, in the course of time" [9].

The theatre performance has never been, nor can it be at present day, the only true subject of reflection on the theatre and its "contrast, intangible nature" [10]. Theatre performance, as well as all the other scene events, falls into the category of works of art that create "an artificial world, but aware of its artificiality and unswerving in its artificial nature, and so, therefore, also truthful" [11]. The performance is not a material product, so it is not possible to preserve it. Artefacts used to furnish the stage, although material objects, reveal their entire worth exclusively on the stage, during the time of the performance. Thus, even in ideal conditions in the gallery it is not possible to completely represent the elements, and especially not the entirety of a theatrical set design, for example, no matter how technologically complex and well supported the gallery exhibition might be. Years of experience in the presentation and evaluation of performing arts in the past six "editions" of the Biennial of Stage Design, a major national events in the domain of set design, costume design, theatre architecture, applied performing arts, crafts 
and promoting events, clearly proved that the relevant attitude towards these works can be formed only through direct personal experience of theatrical performance and its overall structure. The experience of all previous selectors of the Biennale confirms that documents have value only as a supplement, and not as a substitute for direct insight into the theatre production. The means by which the performance can be documented (photographs, audio and video recordings, models, documentation following the making of set design, books of directors and writers actions, newspaper reviews and expert appraisals ...) belong to separate domains and media, they have a purpose, language and rules, they exist to support the theatre performance and its evaluation, but generally they are not adequate representatives neither of the means, nor of the language or the laws of theatre. In addition, the documentation does not include the conditionality and the conventions that govern the process of creating a theatre performance by definition and form the basis of perception, experience and readings of theatrical works. "You see it, and it is no more: the dramatic text itself will never tell a completely identical story, and the set design and props are not enough to set up a scene. Since the theatre does not have a physical bequest, the theatre house remains its only creative legacy" [10].

However, the most important legacies of the theatre are the ideas about the theatre, "what is the counterpoint in music - nothing by itself, but the sine qua non for all." [12]. The idea of theatre is conveyed through houses, books, research documents, history and theory, but it is also conveyed through "theatre people". This concept, can be and must be understood the two ways: as a guideline for a highly heterogeneous and inarticulate "global tribe", and at the same time, as the common name for members of a particular theatre - the theatre as a troupe, or theatre as a movement, but mostly the theatre as an institution of what we often call "the theatre house". In this phrase the term "house" has a direct and a metaphorical meaning. And that is one of the most complex aspects of existence and interpretation of theatre at all times, in all the traditional lines of development and in all meridians. Thus, the causal system of relationships between the theatre house, theatre people and theatre as an idea (or the idea of theatre) is the central theme of my understanding of the definitions, values and purpose of theatre.

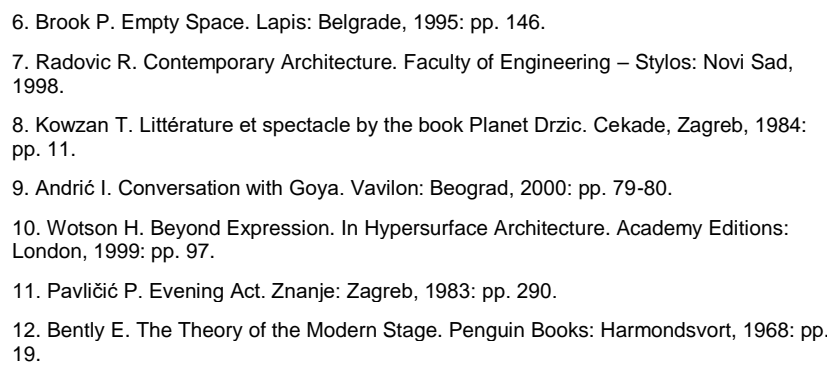

